\title{
An Elegant Impulser Developed for Flat Beam Injection
}

\author{
Michael J. Wilson \\ David A. Goerz \\ Ron D. Speer
}

This paper was prepared for submittal to the 1998 23rd International Power Modulator Symposium

Rancho Mirage, CA

June 22-25, 1998

May 26, 1998

This is a preprint of a paper intended for publication in a journal or proceedings. Since changes may be made before publication, this preprint is made available with the understanding that it will not be cited or reproduced without the permission of the author. 


\section{DISCLAIMER}

This document was prepared as an account of work sponsored by an agency of the United States Government. Neither the United States Government nor the University of California nor any of their employees, makes any warranty, express or implied, or assumes any legal liability or responsibility for the accuracy, completeness, or usefulness of any information, apparatus, product, or process

disclosed, or represents that its use would not infringe privately owned rights. Reference herein to any specific commercial product, process, or service by trade name, trademark, manufacturer, or otherwise, does not necessarily constitute or imply its endorsement, recommendation, or favoring by the United States Government or the University of California. The views and opinions of authors expressed herein do not necessarily state or reflect those of the United States Government or the University of California, and shall not be used for advertising or product endorsement purposes. 


\title{
An Elegant Impulser Developed for Flat Beam Injection*
}

\author{
Michael J. Wilson, David A. Goerz, and Ron D. Speer \\ Lawrence Livermore National Laboratory \\ Livermore, California 94550-9900
}

\begin{abstract}
The following report describes the design, construction, and checkout of a high-voltage (HV) impulser built for the heavy ion fusion (HIF) project [1]. The purpose of this impulser is to provide an adjustable diode voltage source of sufficient quality and level to allow the optimization of beam transport and accelerator sections of HIF [2, 3]. An elegant, low-impedance, high-energy storage capacitor circuit has been selected for this application. Circuit parameters of the retrofit to the diode region [4] have been included to provide the controlled rise time. The critical part of this circuit that is common to all candidates is the impedance matching component. The following report provides a description of the implemented circuit, the basic circuit variables for wave shaping, screening techniques revealing the weakest circuit component, and the resulting output of the injector.
\end{abstract}

\section{INTRODUCTION}

The purpose of this effort is to provide a regulated impulse to a thermionic diode. The diode provides the ion beam foundation for HIF. The quality of the impulse regulation directly affects the initial beam profile and the required complexity of the acceleration section. Poor beam quality prematurely compromises the level of acceleration to the beam instability level. Table 1 summarizes the design requirements of the injector.

Several approaches used to meet the impulse requirements have shown modest success at limited levels. An elegant low-impedance source was selected as the workhorse for the impulser. Screening major components exposes weak components and shows areas for improvement. The general requirement to control the diode electrical characteristics provided the insight to high beam quality.

Table 1 Initial engineering design requirements used to develop the proper impulse generator for the HIF project.

\begin{tabular}{|l|c|c|c|c|}
\hline \multicolumn{1}{|c|}{ Parameter } & Units & \multicolumn{3}{c|}{ Value } \\
\hline \multicolumn{1}{|c|}{ shape/polarity } & square wave/positive & minimum & nominal & maximum \\
\hline \hline Flat Top Voltage (FTV) & $\mathrm{kV}$ & 75 & 80 & 120 \\
\hline pulse width & $\mu \mathrm{s}$ & 1 & 5 & 6 \\
\hline rise time (10-90\%) @ $80 \mathrm{kV}$ & $\mathrm{ns}(\mathrm{min} / \max 5 \%)$ & 310 & 326 & 342 \\
\hline rise time (10-90\%) @ $100 \mathrm{kV}$ & $\mathrm{ns}(\min / \max 5 \%)$ & 277 & 292 & 307 \\
\hline fall time (10-90\%) @ $80 \mathrm{kV}$ & $\mathrm{ns}(\mathrm{min} / \max 5 \%)$ & 310 & 326 & 342 \\
\hline fall time (10-90\%) @ $100 \mathrm{kV}$ & $\mathrm{ns}(\min / \max 5 \%)$ & 277 & 292 & 307 \\
\hline overshoot & $\%$ of nominal FTV & & 1 & 2 \\
\hline ripple & $\%$ of nominal FTV & & & 0.1 \\
\hline Flatness (droop) over 5 $\mu \mathrm{s}$ & $\%$ nominal FTV & & 0.5 & \\
\hline jitter (pulse to pulse) & $\mathrm{ns}$ & & 20 & 50 \\
\hline repetition rate & $\mathrm{Hz}$ & & 1 & \\
\hline
\end{tabular}

\footnotetext{
* Work performed under the auspices of the U. S. Department of Energy by the Lawrence Livermore National Laboratory under Contract W-7405-Eng-48.
} 


\section{Impulser}

A system-level look at the diode or load requirements exposed an inherent problem with mismatched impedances. The basic solution to resolve the diode parameter requirement is applicable to any selected impulse technology. The following circuit shown in Figure 1 represents the first order approach to provide a stiff source as the impulser.

The basic circuit consists of a $100 \mathrm{nF} / 200 \mathrm{kV}$ capacitor (C1), a series UV-illuminated gas switch (S1), and impedance matching resistor (R3), a variable augmenting diode capacitor (C2), a robust crowbar switch (S2), and a crowbar resistor (R2). The interconnections are defined by inductance ( $L 1, L 2$, and $L 3$ ). The rise time is adjusted to the desired profile with L3 and C2. The overshoot is controlled by the proper selection of R3. The impedance of the interconnection L3 to the diode and capacitance $\mathrm{C} 2$ defines the value of R3.

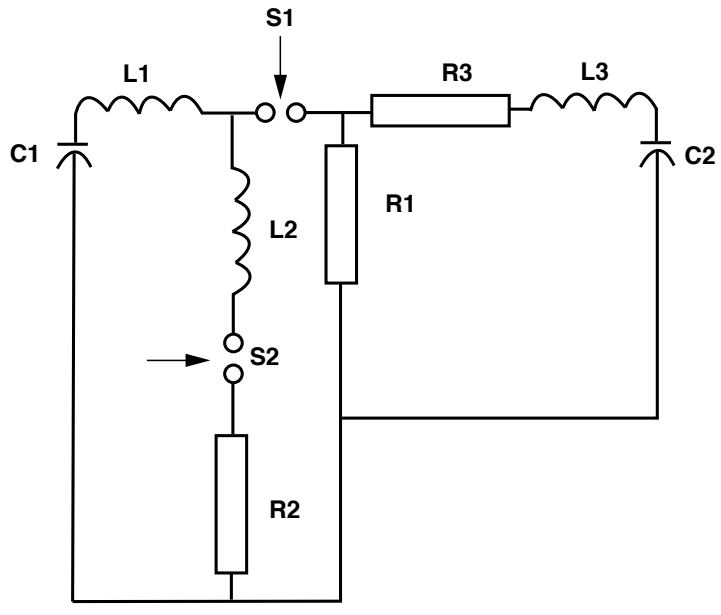

Figure 1 The above figure illustrates the basic circuit used as the HIF diode impulser.

Critical to the proper operation of this type of circuit is the selection of R3. The parameter that is controlled by this decoupling component is the overshoot. The optimum value for this component is given by the following relationship:

$$
R 3=2.3 \times \sqrt{\frac{L 3}{C 2}}
$$

In addition:

$$
\begin{array}{llrl}
\mathrm{C} 1 & =100 \mathrm{nF} & \mathrm{C} 2 & =10 \mathrm{nF} \\
\mathrm{L} 1 & =200 \mathrm{nH} & \mathrm{L} 2 & =200 \mathrm{nH} \\
\mathrm{L} 3 & =1.3 \mu \mathrm{H} & \mathrm{R} 1=100 \mathrm{k} \Omega \\
\mathrm{R} 2=3 \Omega & \mathrm{R} 3=26.2 \Omega
\end{array}
$$

S1-Provides for the initiation of the impulse into the load.

S2-Provides for a triggered crowbar before diode closure. The final circuit may incorporate a fault detector to ensure that if diode closure does occur, then the crowbar will activate and discharge the system in approximately 500 ns.

Consider the test configuration with an initial charge voltage of $100 \mathrm{kV}$, and a selected C2 of $10 \mathrm{nF}$. The impulser with a selected width of $5 \mu \mathrm{s}$ will have 500 joules (J) stored in $\mathrm{C} 1$ and transfer $50 \mathrm{~J}$ into $\mathrm{C2}$. The pulse width is only given as a reference and needed to view any power issues. $A$ diode intrinsic capacitance of $100 \mathrm{pF}$ will store $0.5 \mathrm{~J}$ at $100 \mathrm{kV}$. C2 becomes the main energy storage component in the diode region. The energy stored in $\mathrm{C} 2$ discharges through $\mathrm{R} 2$ and $\mathrm{R} 3$ at a rate defined by L3 and C2. Consider that L3 with a length of one-meter has an inductance of approximately $1.3 \mu \mathrm{H}$. The resulting frequency is defined by the following relationship:

$$
F=\frac{1}{2 \pi \sqrt{L C}}
$$

The resulting frequency is $1.4 \mathrm{MHz}$ with a period of $720 \mathrm{~ns}$. The contributing factor of L3 to the discharging impedance is given by $\omega \mathrm{L}$, which for this case is $14 \Omega$. The dynamic impedance of L3 and $\mathrm{C} 2$ given by the square root of the ratio of L3 to $\mathrm{C} 2$ is $11.4 \Omega$. The combined $\mathrm{R} 2$ an $\mathrm{R} 3$ value is nominally $29 \Omega$. The resulting $Q$ of the circuit is slightly greater than 2 . The effect of this to the discharge characteristics of the diode will be similar to those of the impulse charging and limit the undershoot during the crowbar phase. The result is a fall time on the diode approximately equal to the rise time.

This approach provided an elegant solution to the impulser requirements in a timely fashion. The selected circuit components provided a robust design that should provide a reasonable project evaluation tool. The next generation of impulsers required beyond the immediate project needs should take these issues into consideration as an integrated approach to an engineered injection diode.

\section{Impulser Layout}

The initial intent of the impulser layout was to reduce the overall package of the unit and relax the need for an oil environment. The typical packaging of choice is pressurized gases. 
Figure 2 illustrates a compact topology to fit into a reasonable environmental chamber. Shown are the energy storage capacitors, series and crowbar switches, an internal voltage probe on the series switch output, triggering inputs, and the first set of crowbar resistors. A compromise use of oil was required to accommodate the HV-bushing/filament vacuum interface. This insulator is not rated for pressure greater than an atmosphere. Fit-up and checkout of the impulser was done in a 55-gallon barrel providing a reasonable compact topology.

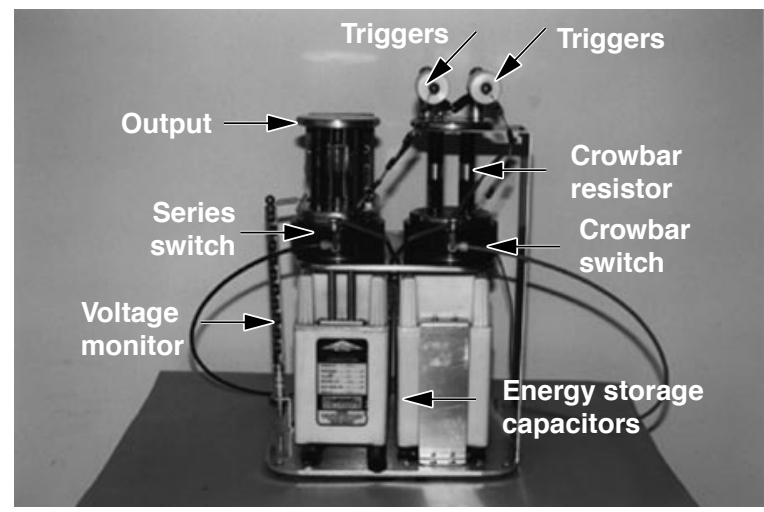

Figure 2 The above photo illustrates a compact package technique. The design of this package allows operation to $50 \mathrm{kV}$ in one atmosphere of air and higher levels in SF6 or oil environments.

\section{Major Component Screening}

Three major components in the impulser were screened to improve system reliability. These components were the $40-\mathrm{nF} / 100 \mathrm{kV}$ energy storage capacitor, the $3-\mathrm{nF} / 40 \mathrm{kV}$ pulse shaping capacitors, and the $100 \mathrm{kV}$ crowbar gas switch. The following section describes the screening process and related information to the weakest component the principal energy storage capacitor.

Ten 40-nF/100 kV capacitors provide the primary energy stage for this impulser. The $120 \mathrm{kV}$ upper level of desired operation provided a design safety margin of 2 for the main storage section $\mathrm{C} 1$, as previously defined. The initial configuration required that the capacitor be qualified for a gas environment. The units were cleaned of surface contaminates then screened in a vacuum chamber by evacuating each unit to -28 inches of $\mathrm{Hg}$. Qualified candidates were then installed in six atmospheres of SF6 and elevated to $100 \mathrm{kV}$ at a nominal rate of $50 \mathrm{kV} / \mathrm{sec}$. Twelve exposures to this level were made on each component while measuring the current. The screening criteria of this step was to ensure that no unit exhibited an abnormal amount of leakage current after being charged to $100 \mathrm{kV}$ during a two-second stress level. Figures 3 and 4 show a representative charge voltage and current of a sample component, respectively. The selected value for C1 consisted of an array of two $40-n F / 100 \mathrm{kV}$ capacitors connected in series. As mentioned above, this provided a nominal design safety margin of two for these components.

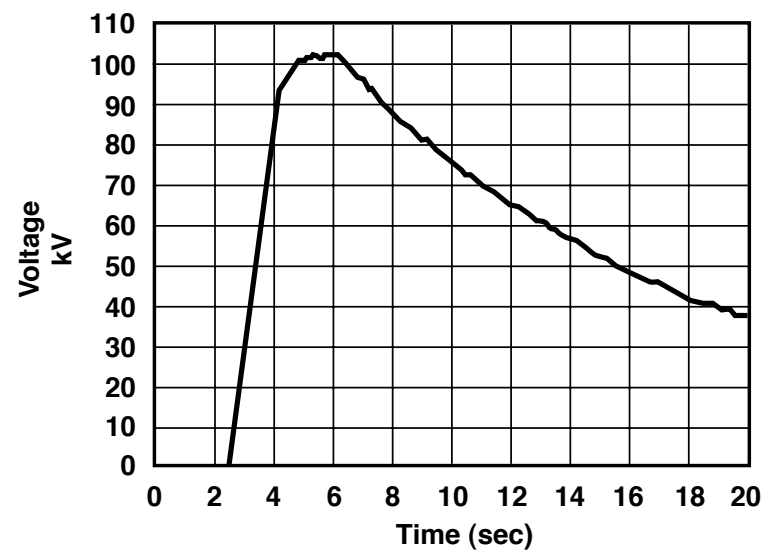

Figure 3 The above wave shape provides a typical view of the applied voltage to a 40$\mathrm{nF} / 100 \mathrm{kV}$ oil filled capacitor.

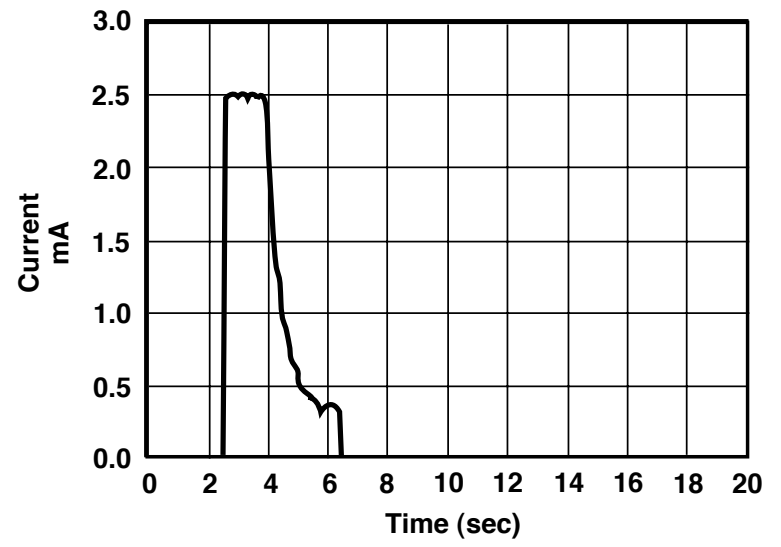

Figure 4 The above wave shape provides a typical view of the charge current to a capacitor during the screening process.

As indicated in Figure 4, the nominal leakage of the selected capacitors was $0.3 \mathrm{~mA}$ at $100 \mathrm{kV}$. As a result of this excessive leakage current, 25 watts of power was dissipated inside the capacitor. A process to reduce these internal losses has been developed by LLNL [5]. Ten capacitors of the current available units had a combined leakage of $3 \mathrm{~mA}$. This indicates that a power supply minimum requirement for operation at $100 \mathrm{kV}$ would have 
an impedance of $33 \mathrm{M} \Omega$ and a minimum power requirement of $300 \mathrm{~W}$. A $2 \mathrm{~kW} / 125 \mathrm{kV}$ Glassman power supply is used to support the impulser. The combined trigger circuit bias strings of $50-\mathrm{M} \Omega$ total gave additional power supply loading during the charge phase of operation. The equivalent loading to the power supply became nominally $20 \mathrm{M} \Omega$, and at $100 \mathrm{kV}$ consumes $500 \mathrm{~W}$ of power per shot. Added to the system-operating requirement of $500 \mathrm{~J}$ per shot, the maximum repetition rate of the circuit became $2 \mathrm{~Hz}$ for the given power supply. Open circuit measurements showed that the measured voltages and currents on the screened components were representative of the device under test (DUT) and not the test circuit. The measured current in the test fixture is 10,000 less than that measured across the DUT. As a result, all the current measured in the screening process was considered to be in the screened component.

A review of the selected capacitor information provided from Maxwell Laboratories, Inc. indicated that the units are rated for a $1 \mathrm{~Hz}$ operation. This specification is at full rated voltage and voltage reversal $<20 \%$. The resulting effects of a $2 \mathrm{~Hz}$ operation at $40 \%$ reduced operating voltage and minimal voltage reversal did not seem to be an issue. The slight reduction in the operating voltage does provide an estimated increase in the life expectancy by a factor of five. The anticipated life of $90 \%$ of the capacitors became $1.5 \times 10^{5}$ discharges with these operating parameters. This is not adequate for a production-type application, but provides the needed information for the proof of concept.

\section{System Operation}

This section discusses the operation of the impulser. The intent of this robust design is to provide a reasonable tool to conduct experiments. As mentioned above, some of the selected components do not have the projected life expectancy desired for a final design but they will help establish the specific design requirements for the next generation.

The tuning of the impulse shaping components is done at air and reduced voltage to ensure that the diode does not close. The design impulse profile does not require the use of a high fidelity probe, a Tektronix P-6015A or equivalent will easily suffice. Figure 5 indicates the voltage measured across the diode. The impulse width is longer than required to illustrate the impulse quality.

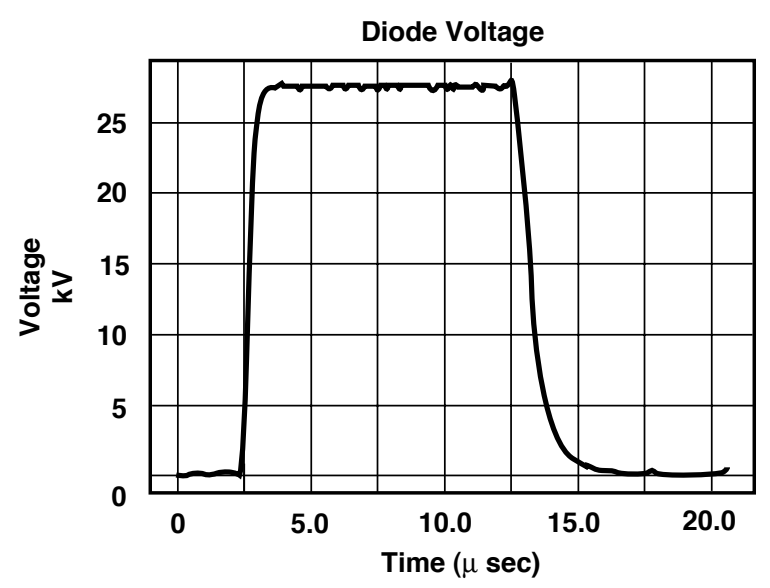

Figure 5 The above wave shape provides a typical measurement of the voltage across the diode as measured by a Tektronix highvoltage probe.

\section{Conclusion}

High quality ion-injectors are possible when the design considerations include driver and load reflections caused by impedance mismatches. Simple circuits are easily fabricated to deliver required profiles. Limitations for long life highcurrent sources are main energy storage devices and switching gear. Hard-tube modulators represent the next level of injectors to achieve production like reliability and repetition rates.

\section{Reference}

[1] J. J. Barnard, et al., "Recirculating Induction Accelerators for Heavy Ion Fusion," in The Proceedings of the International Symposium on Heavy lon Inertial Fusion, Frascati, Italy, May 25-28, 1993.

[2] A. Friedman, et al., "Progress Toward a Prototype Recirculating Induction Accelerator for Heavy-Ion Fusion," in The Proceeding of the IEEE 1995 Particle Accelerator Conference, Dallas, TX, May 1-5, 1995.

[3] Michael J. Wilson, et al., Heavy Ion Fusion (HIF) Impulse Injector Design, Construction, and Checkout, Lawrence Livermore National Laboratory, UCRL-ID130764, May 1998.

[4] David A. Goerz and Michael J. Wilson, "Improving Ion Beam Injector Performance By Augmenting Capacitance of Vacuum Diode," in The 1998, 23rd International Power Modulator Symposium; Rancho Mirage, California, USA; June 22-25, 1998.

[5] Michael J. Wilson and David A. Goerz, "Compact High-Voltage Structures," in The 1997, 11th IEEE International Pulsed Power Conference, Baltimore, MD, pp. 1596-1601. 


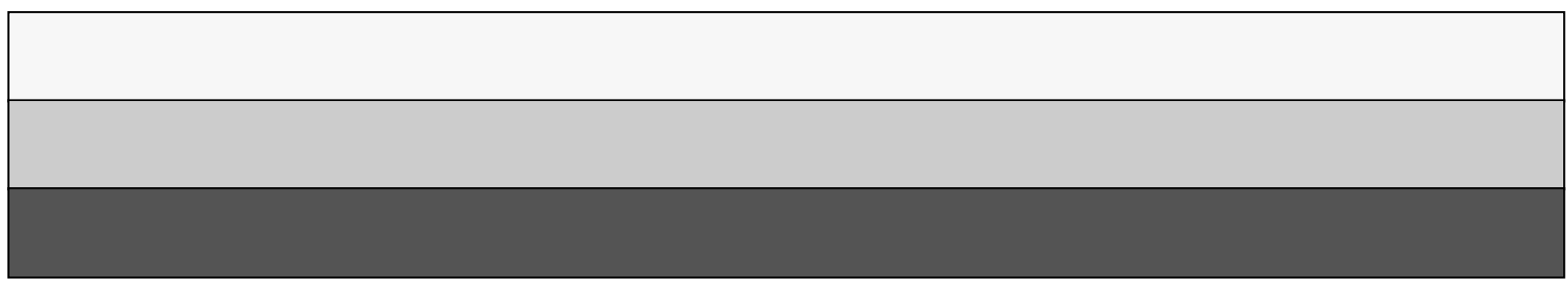

